\title{
Microampere electric currents caused bacterial membrane damage and two-way leakage in short time
}

V R Krishnamurthi A Rogers J Peifer I Niyonshuti J Chen Y Wang 


\section{Abstract}

Physical agents such as low electric voltages and currents have recently gained attention for antimicrobial treatment due to their bactericidal capability. Although microampere electric currents were shown to suppress the growth of bacteria, it remains unclear to what extent the microampere currents damage bacterial membrane. Here, we investigated the membrane damage and two-way leakage caused by microampere electric currents $(\leq 100 \mu \mathrm{A})$ in a short time (30 min). Based on MitoTracker staining, propidium iodide staining, filtration assays, and quantitative single-molecule localization microscopy, we found that microampere electric currents caused significant membrane damages and allowed two-way leakages of ions, small molecules and proteins. This study paves the way to new development and antibiotic applications of ultra-low electric voltages and currents.

Keywords: Ultra-low electric current, super-resolution fluorescence microscopy, singlemolecule localization microscopy, membrane damage, leakage

\section{Statement of Significance}

Previous studies showed that treating bacteria with milliampere electric currents for 72 hours led to significant damages of the bacterial membrane. However, it remains unclear to what extent membrane damages and two-way (i.e. inward and outward) leakages are caused by lower electric currents in a shorter time. In this work, we set out to answer this question. We carried out several assays on the bacteria treated by microampere electric currents of $\leq 100 \mu \mathrm{A}$ for $30 \mathrm{~min}$, including MitoTracker staining, propidium iodide staining, filtration assays, and quantitative single-molecule localization microscopy. We found and quantified that the membrane damages were caused by microampere electric currents in half an hour and allowed two-way leakages of ions, small molecules, and proteins. 


\section{Introduction}

As antibiotic resistance of bacteria has become one of the biggest threats to public health (1), alternatives to antibiotics have been attracting broad interest and attention $(2,3)$. Physical methods, such as sunlight/UV, fire, drying, high temperature, and high pressure, have played important roles in sterilization and disinfection from very early times of human history (4). Since the 1960s, electric voltages, currents, and fields have been explored as physical means for suppressing the growth of, and/or killing, bacteria. While most of the early studies focused on the bactericidal effects of high electric voltages and currents (58), it was found, more recently, that low electric voltages and currents can also effectively kill bacteria and biofilms (9-27). For example, Pareillexu and Sicard investigated the effects of low electric currents ranging from 10 to 200 milliampere $(\mathrm{mA})$ on the viability Escherichia coli (E. coli) bacteria and found that currents as low as $25 \mathrm{~mA}$ could kill the bacteria (27). The lethal activity of $\mathrm{mA}$ currents were confirmed by various later reports $(9,17-19,25,26)$. In addition, many studies showed that ultra-low electric current at microampere $(\mu \mathrm{A})$ were bactericidal $(10,13,18,20,21,24)$; even electric field (without current) can inhibit the growth of planktonic bacteria (16). Furthermore, electric currents at $\mu \mathrm{A}$ and/or $\mathrm{mA}$ have been applied to, and shown to be effective for treating biofilms (11, $12,14,15,18,22-24,28)$.

Efforts have been made toward understanding the antimicrobial mechanisms of low electric voltages and currents. Possible mechanisms include membrane damage and disruption, reduction in ATP production and enzymatic activities $(17,26)$, and generation of reactive oxygen species (ROS) (13-15). Membrane damages caused by high electric voltages have been well known for a long time. For example, electroporation is a commonly used microbiological technique to deliver DNA and proteins into bacteria and cells by applying high electric voltages at kilovolts (kV) (29-31). More recently, transmission electron microscopy showed that treating bacteria at low electric currents of $5 \mathrm{~mA}$ for $\geq 72$ hours led to significant damages, based on which leakage of cellular contents and influx of toxic substances through the damaged membrane were suggested (17). An interesting follow-up question is to what extent membrane damages and twoway (i.e. inward and outward) leakages are caused by microampere electric currents in a shorter time. Although previous results showed that microampere electric currents were effective for suppressing the growth of bacteria, it remains unclear to what extent the microampere currents damage bacterial membrane. 
In this work, we set out to answer this question by investigating possible membrane damages of bacteria after subjecting the bacteria to microampere electric currents of $\leq$ $100 \mu \mathrm{A}$ (corresponding to voltages $\leq 2.5 \mathrm{~V}$ ) for $30 \mathrm{~min}$. From MitoTracker staining experiments, we observed that treated bacteria showed much higher fluorescent intensities, indicating that bacterial membrane was affected by the electric currents as low as $50 \mu \mathrm{A}$ (or $\approx 1.5 \mathrm{~V}$ ). In addition, using propidium iodide (PI) staining and filtration assays, we found that the membrane damages allowed two-way leakages of ions, small molecules, and even proteins. This observation was confirmed by quantitative singlemolecule localization microscopy, which allowed us to count the number of histone-like nucleoid structuring (H-NS) proteins inside individual bacteria, confirming that the number of $\mathrm{H}-\mathrm{NS}$ proteins per bacterium decreased as the applied microampere electric currents increased. Further quantitative analysis suggested that the organization and clustering of the H-NS proteins were affected by the applied electric currents and voltages. This study highlights that microampere electric currents $(\leq 100 \mu \mathrm{A})$ in short time scales (e.g. $30 \mathrm{~min})$ caused significant membrane damages to allow two-way leakages of ions, small molecules and proteins through the bacterial membrane.

\section{Materials and Methods}

\section{Bacterial strain and growth}

Two K-12 derived $E$. coli strains were used in this study: the first strain is MG1655 (from the Yale Coli Genetic Stock Center) $(32,33)$, and the second strain has the $h n s$ gene on the bacterial DNA fused to meos gene. The second strain expresses fluorescent H-NSmEos3.2 fusion proteins (34), facilitating the fluorescence-based filtration assay and the quantitative single-molecule localization microscopy (34-38).

The bacteria were grown at $37^{\circ} \mathrm{C}$ overnight in defined $\mathrm{M} 9$ minimal medium, supplemented with $1 \%$ glucose, $0.1 \%$ casamino acids, $0.01 \%$ thiamine and appropriate antibiotics with orbital rotation at $250 \mathrm{rpm}(35-37,39)$. On the second day, the overnight culture was diluted by 50 to 100 times into fresh medium so that the OD600 was $0.05(35-37,39)$. The fresh cultures were grown again at $37^{\circ} \mathrm{C}$ in culture tubes equipped with two sterile aluminum electrodes with orbital rotation at $250 \mathrm{rpm}$ without electric voltages or currents (i.e., the wires were shorted, Fig.1A). The resistance of the bacterial cultures $(\approx 32 \mathrm{k} \Omega)$ was measured using a multimeter. When the fresh bacterial culture reached $O D 600 \approx 0.3$, low DC voltages were applied to the culture for $30 \mathrm{~min}(0 \mathrm{~V}$ - untreated negative control, 
$0.5,1,1.5,2$, and $2.5 \mathrm{~V}$, Fig. 1B). The corresponding currents were $0,16,31,47,63$, and $78 \mu \mathrm{A}$, respectively. After the $30 \mathrm{~min}$ treatment, the bacteria were used for the experiments and quantifications as described below.

(A)

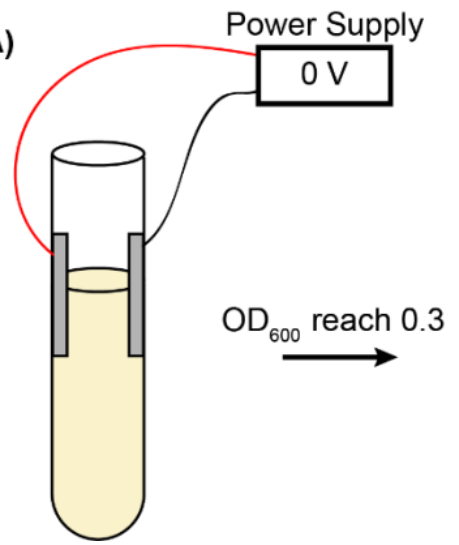

(B)

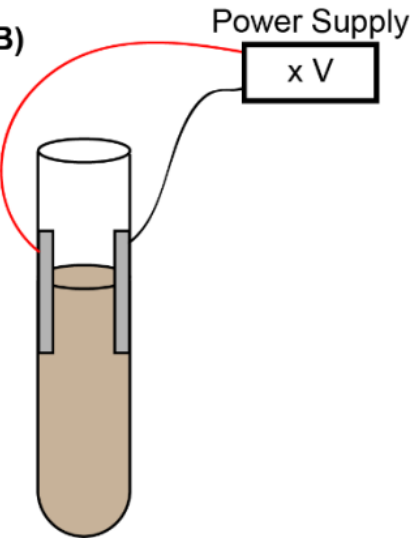

Figure 1. Treating bacteria with low DC voltages. (A) Overnight bacterial culture was diluted in fresh medium and regrew until OD600 reached 0.3 without applying DC voltage $(0 \mathrm{~V})$. (B) Applying low DC voltage $(0.5,1.0,1.5,2.0$, and $2.5 \mathrm{~V})$ on the bacterial culture in culture tubes for $30 \mathrm{~min}$, followed by quantifications.

\section{MitoTracker staining and quantification}

To stain the membrane of bacteria, MitoTracker Green FM dyes (Thermo Fisher Scientific) were added to the untreated and treated bacteria at a final concentration of $300 \mathrm{nM}$, and incubated in a shaking incubator $\left(250 \mathrm{rpm}, 37^{\circ} \mathrm{C}\right)$ for $30 \mathrm{~min}(40) .8 \mu \mathrm{L}$ of the stained bacteria were transferred to $5 \mathrm{~mm} \times 5 \mathrm{~mm}$ agarose pads ( $3 \%$ in $1 \mathrm{X}$ PBS, $\sim 1$ $\mathrm{mm}$ thick) for mounting. The agarose pads with bacteria were flipped and attached to clean coverslips (cleaned with sonication in $1 \mathrm{M} \mathrm{NaOH}, 100 \%$ ethanol, and ultra-pure water sequentially). Chambers were then constructed by sandwiching rubber o-rings between the coverslips and cleaned microscope slides. The chambers were sealed using epoxy glue and then mounted on a microscope for fluorescence imaging (excitation $=488$ $\mathrm{nm}$ ). From the acquired images, the average fluorescence intensities of 100 bacteria treated at each voltage were measured using ImageJ $(41,42)$.

\section{Propidium iodide (PI) staining and quantification}

To measure possible inward leakage due to membrane damage, the untreated and treated bacteria were first fixed by $3.7 \%$ formaldehyde (Sigma-Aldrich) and stained with 
PI (G-Biosciences) $(43,44)$. The PI-stained bacteria were mounted on agarose pads and prepared for fluorescence imaging similar to the MitoTracker experiments, except that the excitation wavelength was changed to $532 \mathrm{~nm}$. The stained cells were counted and their percentages were calculated based on the acquired fluorescence images.

\section{Filtration assays}

Filtration assays to assess the leakage of cellular contents due to membrane damages were performed similar to Ref. (45). Briefly, the untreated and treated bacteria (expressing H-NS-mEos3.2 fusion proteins) were filtered by $0.2 \mu \mathrm{m}$ filters (VWR International LLC), resulting in filtrates constituting leaked cellular contents due to membrane damage, in addition to proteins and molecules from the culture media. For each sample, the filtrate was aliquoted into 96-well plate (200 $\mu \mathrm{L}$ per well), followed by measuring the absorbance at $280 \mathrm{~nm}$ and fluorescence at $525 \mathrm{~nm}$ (excitation = $498 \mathrm{~nm}$ ) on a multi-mode microplate reader (Synergy H1, BioTek).

\section{Quantitative single-molecule localization microscopic assay}

Quantitative single-molecule localization microscopy (46) on the bacteria subjected to microampere electric currents was performed following our previous work $(35-37,39)$. Briefly, the untreated and treated bacteria were first fixed by $3.7 \%$ formaldehyde for 30 min at room temperature and harvested by centrifugation (1000 $\mathrm{g}$ for $10 \mathrm{~min}$ ). The harvested cells were resuspended in $1 \mathrm{X}$ phosphate-buffered saline (PBS) buffer. The centrifugation and resuspension were repeated for three times. The prepared bacteria were mounted on agarose pads for imaging. The single-molecule localization microscope was home-built on an Olympus IX-73 inverted microscope with an Olympus TIRF 100X N.A.=1.49 oil immersion objective. The microscope and data acquisition were controlled by Micro-Manager $(47,48)$. A $405 \mathrm{~nm}$ laser and a $532 \mathrm{~nm}$ laser from a multi-laser system (iChrome MLE, TOPTICA Photonics) were used to "activate" and excite the H-NSmEos3.2 fusion proteins in bacteria. Emissions from the fluorescent proteins were collected by the objective and imaged on an EMCCD camera (Andor) with an exposure time of $30 \mathrm{~ms}$ (the actual interval between frames was $45 \mathrm{~ms}$ ). The effective pixel size of acquired images was $160 \mathrm{~nm}$, while the field of view was $256 \times 256$ pixels.

The resulted movies (20,000 frames) were analyzed with RapidStorm (49), generating $\mathrm{x} / \mathrm{y}$ positions, $\mathrm{x} / \mathrm{y}$ widths, intensity, and background for each detected fluorescent spot. Spots that are too dim, too wide, or too narrow, were rejected (50), followed by drift- 
correction using a mean cross-correlation algorithm (51). The localizations that appear in adjacent frames and within $10 \mathrm{~nm}$ to each other were regrouped as a single molecule (52). The resultant localizations were used for reconstruction of super-resolved images and for further quantitative analysis.

The localizations of $\mathrm{H}-\mathrm{NS}$ molecules from each acquisition were first manually segmented into individual bacterial cells using custom MATLAB programs (35). Analysis and quantification of the spatial organization of $\mathrm{H}-\mathrm{NS}$ proteins were performed on individual cells. Following the segmentation of cells, the number of localizations per bacterium $N_{p}$ was counted (35). In addition, Voronoi-based quantification and clustering analysis were performed using custom MATLAB programs following Levet et al. (53), from which we estimated the molecular density of H-NS proteins $\rho$, the mean inter-neighbor distances $\Delta_{\text {ave }}$, the number of clusters per bacterium $N_{c l}$, the number of proteins per cluster $N_{p c}$, the area of clusters of $\mathrm{H}-\mathrm{NS}$ proteins $A_{c l}$, and the fraction of proteins forming clusters $\phi_{c l}$ $(35,53)$.

\section{Results}

\section{Membrane damage caused by microampere electric currents}

Microampere electric currents were applied to the bacterial culture by applying low electric $\mathrm{DC}$ voltages. As the resistance $(R)$ of the bacterial culture was measured to $\approx 32 \mathrm{k} \Omega$, $\mathrm{DC}$ voltages $(\mathrm{V})$ in the range of $0-2.5 \mathrm{~V}$ resulted in currents $(\mathrm{I})$ of $0-78 \mu \mathrm{A}(\mathrm{I}=\mathrm{V} / \mathrm{R})$. After treatment for $30 \mathrm{~min}$, we stained the bacterial membrane by MitoTracker Green FM dyes (40). As shown in Figs. 2A and 2B, the intensity of the bacterial membrane became higher after subjecting the bacteria to the microampere electric currents. To quantify this observation, we estimated the mean intensities of the bacteria and examined the dependence of the mean intensity on the voltage (Fig. 2C). The intensity increased slightly at $0.5 \mathrm{~V}$ or $16 \mu \mathrm{A}$, indicating changes in the bacterial membrane. With $\geq 1.5 \mathrm{~V}$ or $47 \mu \mathrm{A}$, the average intensity increased to $\geq 4$-fold, while many bacterial showed extremely high brightness (up to 19 times brighter) compared to the negative control, suggesting that many of the treated bacteria had significant changes in their membrane. As previous studies showed that, although controversy exists $(54,55)$, the fluorescence of membraneincorporated MitoTracker Green dyes depends on the membrane potential $(56,57)$, it is possible that the microampere electric currents altered the bacterial membrane potential. 

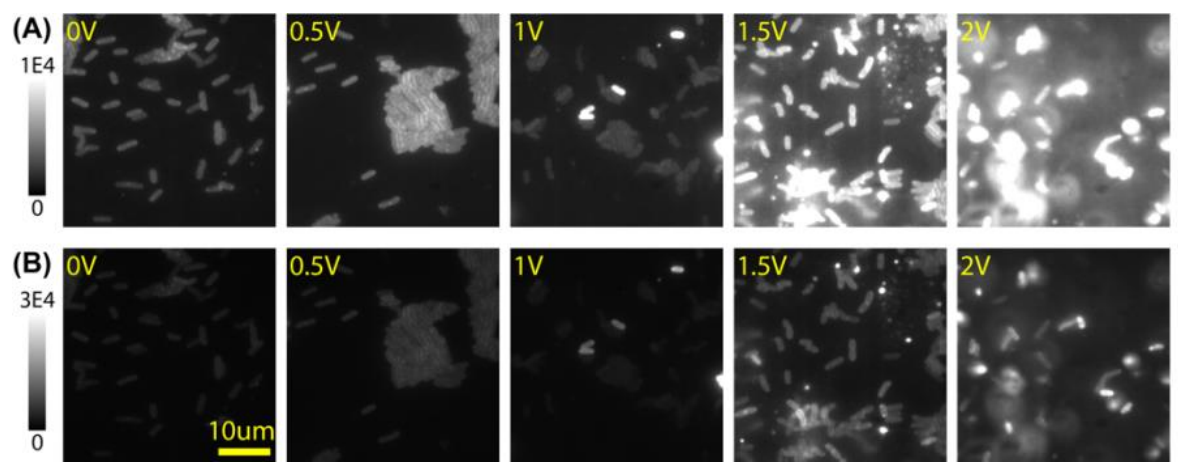

(C)
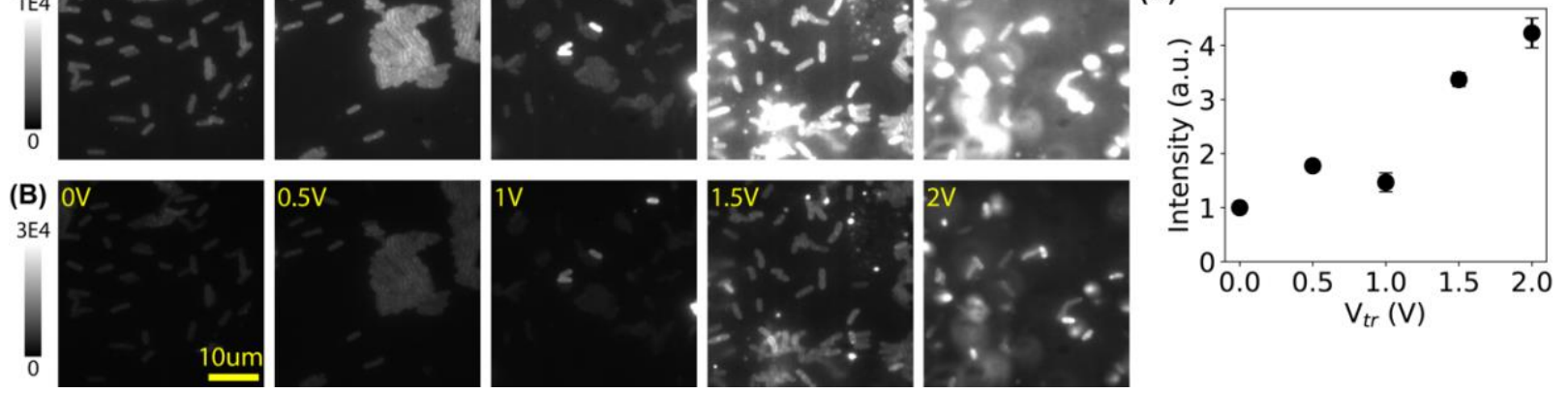

Figure 2. Membrane damage in bacteria caused by microampere electric currents. (A) Representative fluorescence images of bacterial membrane stained by MitoTracker Green FM dyes, after treatment of low DC voltages at $0 \mathrm{~V}$ (untreated negative control) to $2.0 \mathrm{~V}$ (corresponding to $0-63 \mu \mathrm{A}$ ). (B) The same images from panel $\mathrm{A}$, but with a larger intensity scale. $(C)$ Dependence of the mean fluorescence intensity (rescaled by the negative control) on the applied voltage.

\section{Inward leakage due to membrane damage caused by microampere electric currents}

It was previously proposed that membrane damages caused by low electric currents allowed influx of toxicants (17). To test this possibility with microampere electric currents, propidium iodide $(\mathrm{PI})(43,44)$, with a size of $\approx 1 \mathrm{~nm}$, was used to stain the DNA of the bacteria after treatment by microampere electric currents. The rationale is that, if the electrically induced membrane damages allow PI to enter the bacteria to stain DNA, influx of ions and other small organic molecules would also be possible. Representative images of untreated $(0 \mathrm{~V}$ or $0 \mu \mathrm{A})$ and treated $(0.5-2.5 \mathrm{~V}$ or $16-78 \mu \mathrm{A})$ bacteria are shown in Fig. $3 \mathrm{~A}$, where the fluorescent images from PI staining (red) are superposed on the inverted phase contrast images (blue). It was observed that more bacteria were stained by $\mathrm{PI}$ at higher voltages and currents. Quantifying the percentage of PI-stained bacteria $\left(\mathrm{P}_{\mathrm{pi}}\right)$ showed that the percentage of membrane-damaged bacteria increased quickly from $20 \%$ to $\approx 80 \%$ at $1.5-2 \mathrm{~V}$ or $47-63 \mu \mathrm{A}$ (Fig. $3 \mathrm{~B}$ ). This observation confirmed that the membrane damages caused by microampere electric currents are significant enough to enable inward leakage of at least ions and small molecules with a size of $\leq 1 \mathrm{~nm}$. 

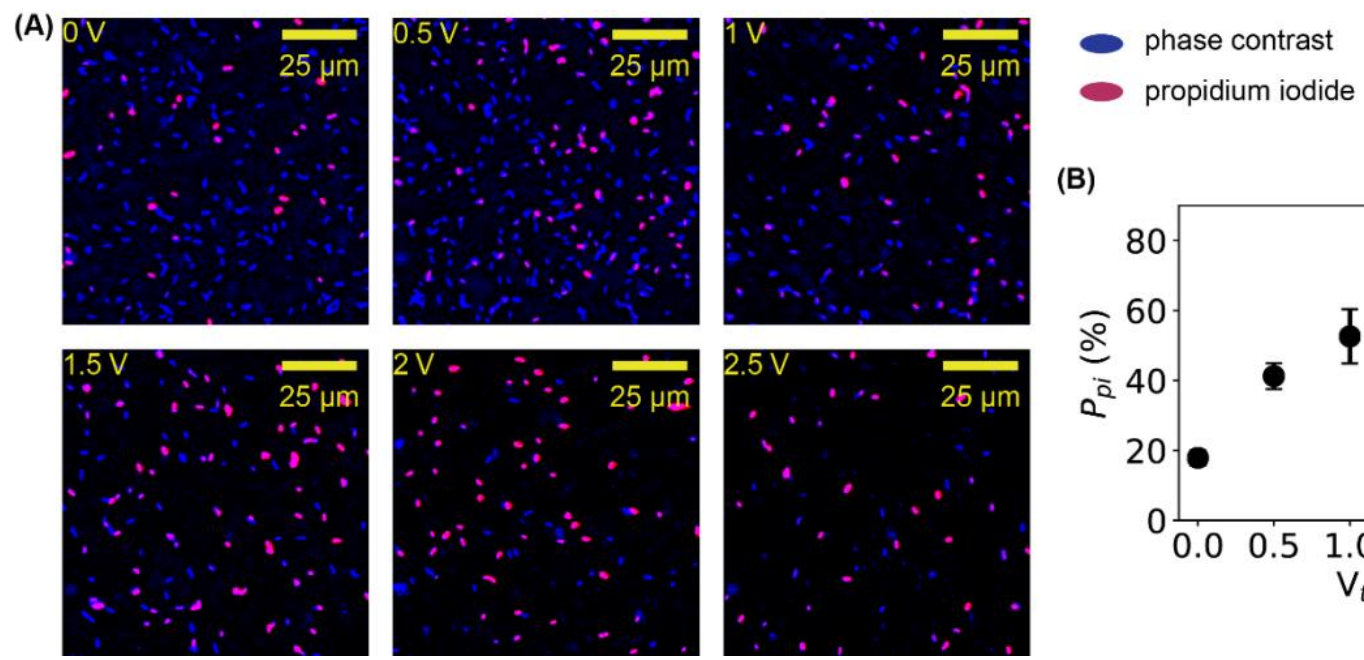

(B)

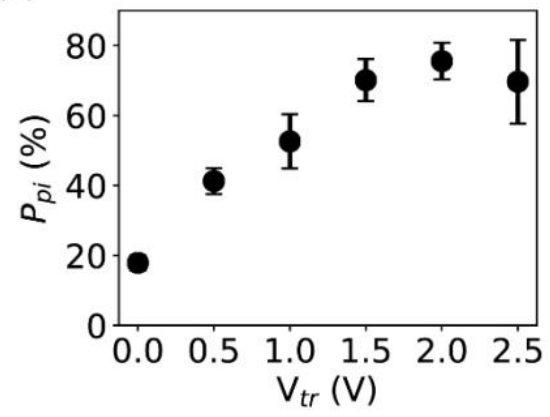

Figure 3. Quantification of inward leakage due to membrane damage by PI staining. (A) Representative fluorescence images (red) of bacteria stained by PI before and after treatment of electric treatment, superposed on the inverted phase contrast images (blue) of the bacteria in the same fields of views. (B) Dependence of the percentage of PIstainable bacteria on the applied voltage.

\section{Outward leakage due to membrane damage caused by microampere electric currents}

Our Pl-staining result showed that influx of ions and small organic molecules $(\leq 1 \mathrm{~nm})$ was possible due to membrane damages caused by microampere electric currents, which also implies that small cellular contents, including amino acids, could leak out of the bacteria. Another question is whether biological macromolecules, such as proteins and nucleic acids, leak out of the bacteria due to the membrane damages caused by microampere electric currents. To answer this question, we adopted a filtration assay that was used to study the membrane damages caused by carbon nanotubes (45). Briefly, the treated bacteria were filtered by $0.2 \mu \mathrm{m}$ filters, and the absorbance of the filtrates was measured at $280 \mathrm{~nm}$, at which both nucleic acids and proteins absorb. We then estimated the relative changes by $\delta A_{280}=\left(\frac{A_{280}^{+}}{A_{280}^{-}}-1\right) \times 100 \%$, where $A_{280}^{-}$and $A_{280}^{+}$are the absorbances at $280 \mathrm{~nm}$ of the filtrates for bacteria before and after microampere current treatment, respectively. A slight increase ( 1\%) was observed (Fig. 4A), providing weak evidence of possible outward leakage of macromolecules. Because the "background" from the culture media could contribute significantly to the absorbance, it is likely that the measured increase in the absorbance was underestimated. 
(A)



(B)

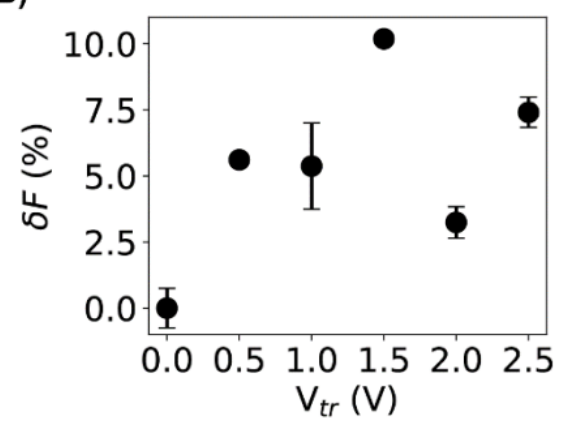

Figure 4. Quantification of outward leakage of bacterial content due to membrane damage by the filtration assays. (A, B) Relative changes in the (A) absorbance at $280 \mathrm{~nm}$ and (B) fluorescence of the filtrates of bacteria samples before and after electric treatment.

To lower the "background" due to the culture media, a modified filtration assay based on fluorescence was performed using an $E$. coli strain that expresses histone-like nucleoid structuring (H-NS) proteins fused to mEos3.2 fluorescent proteins (34). The fluorescencebased filtration assay allowed us to measure the outward leakage of proteins more specifically. By quantifying the relative changes in the fluorescence intensities of the filtrates, $\delta F=\left(\frac{F^{+}}{F^{-}}-1\right) \times 100 \%$, where $F^{-}$and $F^{+}$are the fluorescence of the filtrates for samples before and after microampere current treatment, respectively, we observed an increase of $\sim 10 \%$ for bacteria treated at $2.5 \mathrm{~V}$ or $78 \mu \mathrm{A}$. This observation suggested that the membrane damages caused by the microampere electric currents were significant enough to allow proteins to leak out of the bacteria.

\section{Quantification of protein leakage by single-molecule localization microscopy}

The filtration assays suggested that proteins leaked out of bacteria after treating the bacteria by $\leq 100 \mu \mathrm{A}$ DC currents. To further confirm such protein leakage, we measured the number of the histone-like nucleoid structuring (H-NS) proteins inside individual bacteria before and after microampere current treatment for $30 \mathrm{~min}$ using single-molecule localization microscopy (SMLM) $(46,50,58,59)$. SMLM is one type of super-resolution fluorescence microscopy that localizes individual molecules of interest with a precision of $\leq 10 \mathrm{~nm}$ (60); therefore, it not only produces super-resolved images with high spatial resolution, but also provides a convenient way to count the number of molecules. Without applying sophisticated algorithms (61-63), the number of molecules of interest is on 
average proportional to the intensity in the super-resolved images or the number of localizations obtained by SMLM (39).

We performed single-molecule localization microscopy on untreated and treated bacteria, using the E. coli strain expressing H-NS-mEos3.2 fusion proteins, as mEos3.2 fluorescent proteins are photoactivable and allow super-resolution imaging (34, 35). Representative images of $\mathrm{H}-\mathrm{NS}$ proteins in untreated and treated bacteria are shown in Fig. 5A. For the untreated negative control, $\mathrm{H}$-NS proteins were organized as clusters inside the bacteria (first column in Fig. 5A and 5B), consistent with previously reported results $(35,36,38)$. After subjecting the bacteria to $D C$ voltages of $1-2.5 \mathrm{~V}$ (or currents of $31-78 \mu \mathrm{A}$ ), the intensities on the super-resolved images became significantly dimmer (columns 3-6 in Fig. 5A and 5B). As the intensity in super-resolved images correlates with the probability of localizing the molecules of interest, this result indicates that less H-NS proteins were present in the bacteria after treating the bacteria with microampere electric currents.

To quantify this result, we segmented the bacteria (35) and counted the number of localizations of H-NS proteins in each cell, $N_{p}$. Due to the stochastic nature in the activation and detection of the mEos3.2 fluorescent proteins, $N_{p}$ is expected to be proportional to, on average, the number of $\mathrm{H}$-NS proteins in the bacteria $(35,39)$. The histograms of $N_{p}$ are shown in the inset of Fig. 5C, where the baselines of the histograms were vertically shifted for better visualization of the differences. It is clear that the peaks of the $N_{p}$ distributions translated to the left as the applied voltage increased, suggesting that the number of $\mathrm{H}-\mathrm{NS}$ proteins per bacterial cell decreased when subjecting the bacteria to the low DC voltages and currents. We also calculated the mean of $N_{p}$ and standard error of the mean (SEM) for each sample. Note that, as the distributions of $N_{p}$ were bell-shaped in the linear-log scale (inset of Fig. 5C), we estimated the mean of $\log \left(N_{p}\right)$ and then calculated the mean of $N_{p}$ from $N_{p}=\exp \left(\log \left(N_{p}\right)\right)$. As shown in (Fig. $5 \mathrm{C}$ ), the average number of $\mathrm{H}-\mathrm{NS}$ proteins per cell decreased nearly linearly (Fig. 5C). It is also noted that the observed decrease in the number of $\mathrm{H}-\mathrm{NS}$ proteins per bacterial cell is unlikely due to cellular responses (e.g., lower expression level of $\mathrm{H}$-NS proteins) for several reasons. First, the treatment time $(30 \mathrm{~min})$ is relatively short, comparing to the degradation time of proteins in bacteria (hours) (64). Second, our previous work on H-NS proteins in bacteria treated by antibiotic silver ions and silver nanoparticles showed that the number of H-NS proteins did not decrease within several hours (35). Therefore, the 
microscopic data on individual bacteria directly suggested that $\mathrm{H}-\mathrm{NS}$ proteins leaked out of the bacteria after microampere electric current treatment.

(A)

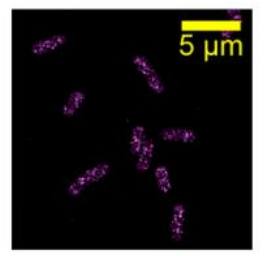

(B)

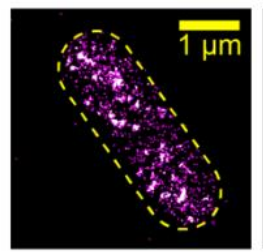

(C)

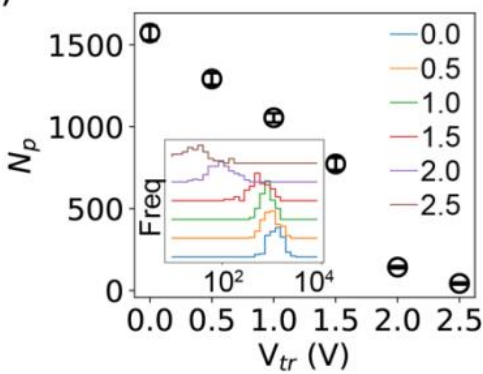

(F)

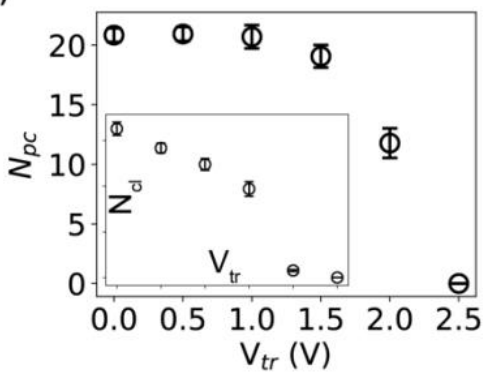

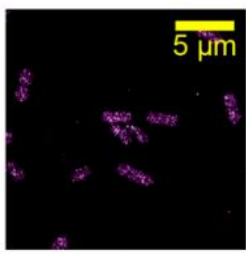

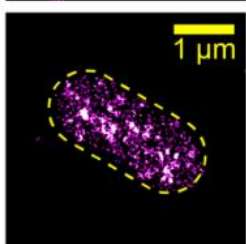

(D)

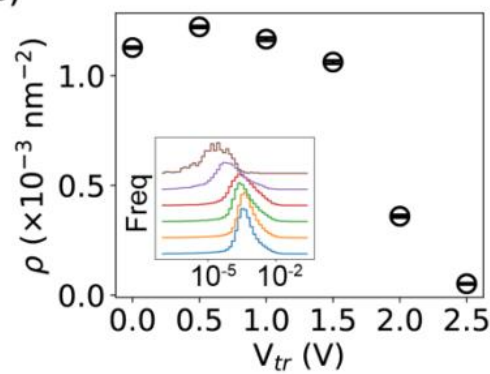

(G)
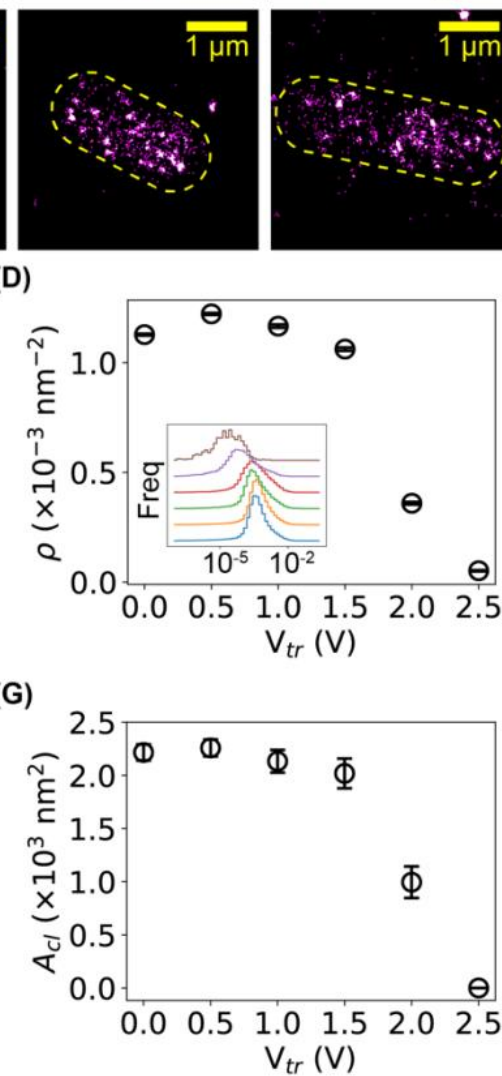
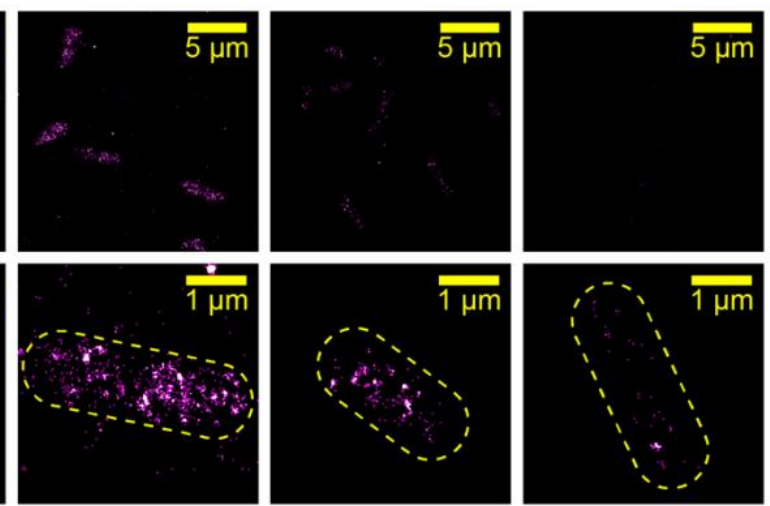

(E)

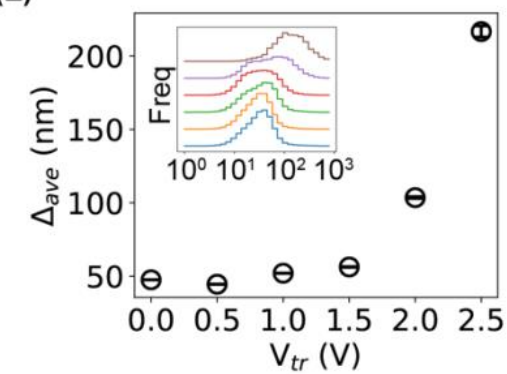

(H)

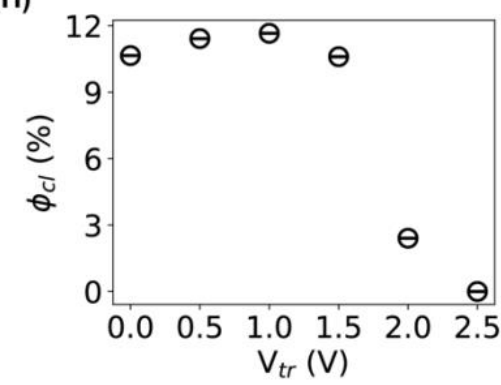

Figure 5. Quantification of outward leakage of bacterial content due to membrane damage by single-molecule localization microscopy. (A) Representative super-resolved images of $\mathrm{H}$-NS proteins in E. coli bacteria before and after electric treatment. Scale bar $=5 \mu \mathrm{m}$. (B) Zoom-in view of super-resolved images showing individual bacteria. Scale bar $=1 \mu \mathrm{m}$. (C - E) Dependence of $(\mathrm{C})$ the number of detected H-NS proteins per cell $\mathrm{Np}_{\mathrm{p}}$ (D) the molecular density $\rho$, and (E) the average inter-molecular distance $\Delta_{\text {ave }}$ on the applied voltage. Insets are the corresponding distributions of the three quantities. Error bars stand for the standard error of the mean (SEM). (F - H) Dependence of $(F)$ the number of clusters per cell $\mathrm{N}_{\mathrm{cl}}$ (inset) and the number of proteins per cluster $\mathrm{N}_{\mathrm{pc}},(\mathrm{G})$ the area of clusters $A_{c l}$, and $(\mathrm{H})$ the fraction of clustering proteins per cell $\phi_{c l}$ on the applied voltage. Error bars stand for SEM. 
We examined how the spatial organization of the H-NS proteins was affected by the electric treatment based on Voronoi diagram tessellation $(35,53)$. We computed the molecular density $(\rho)$ of the H-NS proteins and found that the distribution of $\rho$ shifted to the left, indicating the density decreased as the applied voltage increased (inset of Fig. 5D), which is expected as a result of the decrease of the number of $\mathrm{H}-\mathrm{NS}$ proteins per cell. Interestingly, the mean of the molecular density started to decrease at $1.5-2 \mathrm{~V}$ (or $47-63 \mu \mathrm{A}$ ) as shown in Fig. 5D, which is different from the dependence of the number of $\mathrm{H}-\mathrm{NS}$ proteins per cell on the applied electric voltages and currents (Fig. 5C). We also observed a shift to the right in the distribution of the mean inter-neighbor distances $\Delta_{\text {ave }}$ (inset of Fig. 5E), suggesting that the inter-molecular distances for some H-NS proteins became larger when bacteria were treated by low DC voltages and currents, consistent to the result of the molecular density. In addition, we identified the clusters of $\mathrm{H}-\mathrm{NS}$ proteins based on Voronoi diagrams $(35,53)$ and counted the number of clusters per bacterial cell $\left(N_{c l}\right)$ and the number of proteins per cluster $\left(N_{p c}\right)$. We found that both $N_{c l}$ and $N_{p c}$ decreased after treating the bacteria with DC voltages and currents (Fig. 5F). Furthermore, by quantifying the area of clusters of $\mathrm{H}$-NS proteins, we observed that the $\mathrm{H}-\mathrm{NS}$ clusters became smaller (Fig. 5G). Lastly, we examined the fraction of $\mathrm{H}-\mathrm{NS}$ proteins forming clusters in individual bacteria, $\phi_{c}=N_{c p} / N_{p}$, where $N_{p}$ is the number of localizations (i.e., detected proteins) per cell, and $N_{c p}$ the number of proteins that form clusters in the cell. We observed that the clustering fraction decreased from $10 \%$ for the negative control to $0 \%$ at $2.5 \mathrm{~V}$ or $78 \mu \mathrm{A}$ (Fig. $5 \mathrm{H})$.

\section{Conclusions and Discussions}

To summarize, we investigated the membrane damage of bacteria and the two-way leakage caused by microampere electric currents. We observed that bacteria subjected to $\geq 47 \mu \mathrm{A}$ currents for 30 min showed much higher intensities with MitoTracker staining, suggesting that the bacterial membrane was altered by the microampere electric currents. The microampere current caused membrane damages were large enough to allow PI molecules to enter the bacteria, suggesting that inward leakages of ions and small molecules were possible. In addition, based on filtration assays and super-resolution imaging results, we found that the membrane damages were so significant that proteins leaked out of the bacteria. More importantly, using histone-like nucleoid structuring $(\mathrm{H}$ NS) proteins as an example, we quantified the decrease in the number of $\mathrm{H}$-NS proteins per bacterial cell and characterized the changes in the spatial organization of the $\mathrm{H}-\mathrm{NS}$ 
proteins caused by the electric treatment. This study highlights that treating bacteria with electric currents at $\leq 100 \mu \mathrm{A}$ for 30 min caused significant membrane damage and led to two-way leakages of ions, small molecules and proteins.

It was noted previously that the bactericidal effects of electric voltages and currents are complex, and involve various interactions between the bacteria, electricity, electrode materials and medium (17). For example, in addition to the electrical effects, metal ions released from the electrodes into the medium are likely to affect the growth of bacteria, which has been shown in the literature (65). In addition, ROS generated by the electric voltages and currents could be another significant contributor (13-15). The current study did not aim to distinguish the contributions of these different effects, while these are interesting questions worth pursuing in future investigations. On the other hand, we argue that heating by the electric voltage/current is unlikely to cause damages to the bacteria in this study, because the used electric power is very low. Considering the resistance of the bacterial culture was $\approx 32 \mathrm{k} \Omega$, the electric power was below $200 \mu \mathrm{W}$; at this power, it would take more than one day to heat up the bacterial culture $(5 \mathrm{~mL})$ by one degree.

It is worthwhile to highlight that the electric power leading to serious membrane damages of bacteria is very low, which is expected to facilitate the use of microampere electric currents (and low electric voltages) for antibiotic applications. For example, commonly used household batteries can provide the needed voltages to kill bacteria. More importantly, solar panels have an output power of $\sim 10 \mathrm{~mW}$ per cm2 (66); therefore, a solar panel of $1 \mathrm{~cm} 2$ can easily generate the needed electric power for damaging bacterial membranes, suppressing the growth of bacteria and/or killing bacteria. We anticipate that this study intrigues new development and antibiotic applications of low electric currents.

\section{Acknowledgment}

We thank Dr. Joshua N. Milstein for the generous gift of the E. coli strain expressing mEos3.2-HNS fusion proteins. This work was supported by the University of Arkansas, the Arkansas Biosciences Institute (Grant No. ABI-0189, No. ABI-0226, No. ABI-0277), and the National Science Foundation (Grant No. 1826642). A.R. and J.P. were supported through the Research Experience for Undergraduate program funded by the National Science Foundation (Grant No. 1460754). We are also grateful for supports from the Arkansas High Performance Computing Center (AHPCC), which is funded in part by the 
National Science Foundation (Grants No. 0722625, 0959124, 0963249, 0918970) and the Arkansas Science and Technology Authority.

\section{Author Contributions}

Y.W. and J.C. conceived and planned the experiments. V.R.K. performed all the experiments. V.R.K. J.P and A.R. performed the imaging. V.R.K and Y.W. performed data analysis and interpretation. I.I.N characterized solutions. Y.W., and J.C supervised the project.

\section{References}

1. World Health Organization. 2014. World Health Statistics 2014. World Health Organization.

2. François, B., H.S. Jafri, and M. Bonten. 2016. Alternatives to antibiotics. Intensive Care Med. 42: 2034-2036.

3. Allen, H.K., J. Trachsel, T. Looft, and T.A. Casey. 2014. Finding alternatives to antibiotics. Ann. N. Y. Acad. Sci. 1323: 91-100.

4. Blancou, J. 1995. History of disinfection from early times until the end of the 18th century. Rev. Sci. Tech. 14:21-39.

5. Rosenberg, B., L. Vancamp, and T. Krigas. 1965. Inhibition of cell division in escherichia coli by electrolysis products from a platinum electrode. Nature. 205: 698-699.

6. Sale, A., and W. Hamilton. 1967. Effects of high electric fields on microorganismsl. Killing of bacteria and yeasts. Biochim. Biophys. Acta Gen. Subj. 148: 781-788.

7. Hülsheger, H., J. Potel, and E.G. Niemann. 1981. Killing of bacteria with electric pulses of high field strength. Radiat Environ Biophys. 20: 53-65.

8. Hülsheger, H., J. Potel, and E.G. Niemann. 1983. Electric field effects on bacteria and yeast cells. Radiat Environ Biophys. 22: 149-162.

9. Blenkinsopp, S.A., A.E. Khoury, and J.W. Costerton. 1992. Electrical enhancement of biocide efficacy against Pseudomonas aeruginosa biofilms. Appl. Environ. Microbiol. 58: 3770-3773.

10. Liu, W.K., S.E. Tebbs, P.O. Byrne, and T.S. Elliott. 1993. The effects of electric current on bacteria colonising intravenous catheters. J. Infect. 27: 261-269.

11. Costerton, J.W., B. Ellis, K. Lam, F. Johnson, and A.E. Khoury. 1994. Mechanism 
of electrical enhancement of efficacy of antibiotics in killing biofilm bacteria. Antimicrob. Agents Chemother. 38: 2803-2809.

12. Stoodley, P., D. deBeer, and H.M. Lappin-Scott. 1997. Influence of electric fields and $\mathrm{pH}$ on biofilm structure as related to the bioelectric effect. Antimicrob. Agents Chemother. 41: 1876-1879.

13. Liu, W.K., M.R. Brown, and T.S. Elliott. 1997. Mechanisms of the bactericidal activity of low amperage electric current (DC). J. Antimicrob. Chemother. 39: 687-695.

14. Stewart, P.S., W. Wattanakaroon, L. Goodrum, S.M. Fortun, and B.R. McLeod. 1999. Electrolytic generation of oxygen partially explains electrical enhancement of tobramycin efficacy against Pseudomonas aeruginosa biofilm. Antimicrob. Agents Chemother. 43: 292-296.

15. Brinkman, C.L., S.M. Schmidt-Malan, M.J. Karau, K. Greenwood-Quaintance, D.J. Hassett, J.N. Mandrekar, and R. Patel. 2016. Exposure of bacterial biofilms to electrical current leads to cell death mediated in part by reactive oxygen species. PLoS One. 11: e0168595.

16. Giladi, M., Y. Porat, A. Blatt, Y. Wasserman, E.D. Kirson, E. Dekel, and Y. Palti. 2008. Microbial growth inhibition by alternating electric fields. Antimicrob. Agents Chemother. 52: 3517-3522.

17. Valle, A., E. Zanardini, P. Abbruscato, P. Argenzio, G. Lustrato, G. Ranalli, and C. Sorlini. 2007. Effects of low electric current (LEC) treatment on pure bacterial cultures. J. Appl. Microbiol. 103: 1376-1385.

18. Schmidt-Malan, S.M., M.J. Karau, J. Cede, K.E. Greenwood-Quaintance, C.L. Brinkman, J.N. Mandrekar, and R. Patel. 2015. Antibiofilm Activity of Low-Amperage Continuous and Intermittent Direct Electrical Current. Antimicrob. Agents Chemother. 59: 4610-4615.

19. del Pozo, J.L., M.S. Rouse, J.N. Mandrekar, M.F. Sampedro, J.M. Steckelberg, and R. Patel. 2009. Effect of electrical current on the activities of antimicrobial agents against Pseudomonas aeruginosa, Staphylococcus aureus, and Staphylococcus epidermidis biofilms. Antimicrob. Agents Chemother. 53: 35-40.

20. Del Pozo, J.L., M.S. Rouse, G. Euba, C.-I. Kang, J.N. Mandrekar, J.M. Steckelberg, and R. Patel. 2009. The electricidal effect is active in an experimental model of Staphylococcus epidermidis chronic foreign body osteomyelitis. Antimicrob. Agents Chemother. 53: 4064-4068.

21. van der Borden, A.J., H.C. van der Mei, and H.J. Busscher. 2005. Electric block current induced detachment from surgical stainless steel and decreased viability of Staphylococcus epidermidis. Biomaterials. 26: 6731-6735. 
22. Kim, Y.W., S. Subramanian, K. Gerasopoulos, H. Ben-Yoav, H.-C. Wu, D. Quan, K. Carter, M.T. Meyer, W.E. Bentley, and R. Ghodssi. 2015. Effect of electrical energy on the efficacy of biofilm treatment using the bioelectric effect. npj Biofilms and Microbiomes. 1: 15016.

23. Caubet, R., F. Pedarros-Caubet, M. Chu, E. Freye, M. de Belém Rodrigues, J.M. Moreau, and W.J. Ellison. 2004. A radio frequency electric current enhances antibiotic efficacy against bacterial biofilms. Antimicrob. Agents Chemother. 48: 4662-4664.

24. van der Borden, A.J., H. van der Werf, H.C. van der Mei, and H.J. Busscher. 2004. Electric current-induced detachment of Staphylococcus epidermidis biofilms from surgical stainless steel. Appl. Environ. Microbiol. 70: 6871-6874.

25. Rabinovitch, C., and P.S. Stewart. 2006. Removal and inactivation of Staphylococcus epidermidis biofilms by electrolysis. Appl. Environ. Microbiol. 72: 6364-6366.

26. Ranalli, G., M. Iorizzo, G. Lustrato, E. Zanardini, and L. Grazia. 2002. Effects of low electric treatment on yeast microflora. J. Appl. Microbiol. 93: 877-883.

27. Pareilleux, A., and N. Sicard. 1970. Lethal effects of electric current on Escherichia coli. Appl Microbiol. 19: 421-424.

28. Davis, C.P., S. Weinberg, M.D. Anderson, G.M. Rao, and M.M. Warren. 1989. Effects of microamperage, medium, and bacterial concentration on iontophoretic killing of bacteria in fluid. Antimicrob. Agents Chemother. 33: 442-447.

29. Neumann, E., M. Schaefer-Ridder, Y. Wang, and P.H. Hofschneider. 1982. Gene transfer into mouse lyoma cells by electroporation in high electric fields. EMBO J. 1: 841-845.

30. Dower, W.J., J.F. Miller, and C.W. Ragsdale. 1988. High efficiency transformation of E. coli by high voltage electroporation. Nucleic Acids Res. 16: 6127-6145.

31. Crawford, R., J.P. Torella, L. Aigrain, A. Plochowietz, K. Gryte, S. Uphoff, and A.N. Kapanidis. 2013. Long-lived intracellular single-molecule fluorescence using electroporated molecules. Biophys. J. 105: 2439-2450.

32. Guyer, M.S., R.R. Reed, J.A. Steitz, and K.B. Low. 1981. Identification of a sexfactor-affinity site in E. coli as gamma delta. Cold Spring Harb. Symp. Quant. Biol. 45 Pt 1: 135-140.

33. Jensen, K.F. 1993. The Escherichia coli K-12 "wild types" W3110 and MG1655 have an rph frameshift mutation that leads to pyrimidine starvation due to low pyrE expression levels. J. Bacteriol. 175: 3401-3407.

34. Zhang, M., H. Chang, Y. Zhang, J. Yu, L. Wu, W. Ji, J. Chen, B. Liu, J. Lu, Y. Liu, J. 
Zhang, P. Xu, and T. Xu. 2012. Rational design of true monomeric and bright photoactivatable fluorescent proteins. Nat. Methods. 9: 727-729.

35. Alqahtany, M., P. Khadka, I. Niyonshuti, V.R. Krishnamurthi, A.A. Sadoon, S.D. Challapalli, J. Chen, and Y. Wang. 2019. Nanoscale reorganizations of histone-like nucleoid structuring proteins in Escherichia coli are caused by silver nanoparticles. Nanotechnology. 30: 385101.

36. Sadoon, A.A., and Y. Wang. 2018. Anomalous, non-Gaussian, viscoelastic, and age-dependent dynamics of histonelike nucleoid-structuring proteins in liveEscherichia coli. Phys. Rev. E. 98: 042411.

37. Sadoon, A.A., P. Khadka, J. Freeland, R.K. Gundampati, R.H. Manso, M. Ruiz, V.R. Krishnamurthi, S.K. Thallapuranam, J. Chen, and Y. Wang. 2020. Silver lons Caused Faster Diffusive Dynamics of Histone-Like Nucleoid-Structuring Proteins in Live Bacteria. Appl. Environ. Microbiol. 86.

38. Mazouchi, A., and J.N. Milstein. 2016. Fast Optimized Cluster Algorithm for Localizations (FOCAL): a spatial cluster analysis for super-resolved microscopy. Bioinformatics. 32: 747-754.

39. Wang, Y., P. Penkul, and J.N. Milstein. 2016. Quantitative Localization Microscopy Reveals a Novel Organization of a High-Copy Number Plasmid. Biophys. J. 111: 467-479.

40. Pogliano, J., T.Q. Ho, Z. Zhong, and D.R. Helinski. 2001. Multicopy plasmids are clustered and localized in Escherichia coli. Proc. Natl. Acad. Sci. USA. 98: 44864491.

41. Schneider, C.A., W.S. Rasband, and K.W. Eliceiri. 2012. NIH Image to ImageJ: 25 years of image analysis. Nat. Methods. 9: 671-675.

42. Schindelin, J., I. Arganda-Carreras, E. Frise, V. Kaynig, M. Longair, T. Pietzsch, S. Preibisch, C. Rueden, S. Saalfeld, B. Schmid, J.-Y. Tinevez, D.J. White, V. Hartenstein, K. Eliceiri, P. Tomancak, and A. Cardona. 2012. Fiji: an open-source platform for biological-image analysis. Nat. Methods. 9: 676-682.

43. Rosenberg, M., N.F. Azevedo, and A. Ivask. 2019. Propidium iodide staining underestimates viability of adherent bacterial cells. Sci. Rep. 9: 6483.

44. Boulos, L., M. Prévost, B. Barbeau, J. Coallier, and R. Desjardins. 1999. LIVE/DEAD BacLight : application of a new rapid staining method for direct enumeration of viable and total bacteria in drinking water. J. Microbiol. Methods. 37: 77-86.

45. Chen, H., B. Wang, D. Gao, M. Guan, L. Zheng, H. Ouyang, Z. Chai, Y. Zhao, and W. Feng. 2013. Broad-spectrum antibacterial activity of carbon nanotubes to human gut bacteria. Small. 9: 2735-2746. 
46. Betzig, E., G.H. Patterson, R. Sougrat, O.W. Lindwasser, S. Olenych, J.S. Bonifacino, M.W. Davidson, J. Lippincott-Schwartz, and H.F. Hess. 2006. Imaging intracellular fluorescent proteins at nanometer resolution. Science. 313: 1642-1645.

47. Edelstein, A., N. Amodaj, K. Hoover, R. Vale, and N. Stuurman. 2010. Computer control of microscopes using $\mu$ Manager. Curr. Protoc. Mol. Biol. Chapter 14: Unit14.20.

48. Edelstein, A.D., M.A. Tsuchida, N. Amodaj, H. Pinkard, R.D. Vale, and N. Stuurman. 2014. Advanced methods of microscope control using $\mu$ Manager software. J. Biol. Methods. 1.

49. Wolter, S., A. Löschberger, T. Holm, S. Aufmkolk, M.-C. Dabauvalle, S. van de Linde, and M. Sauer. 2012. rapidSTORM: accurate, fast open-source software for localization microscopy. Nat. Methods. 9: 1040-1041.

50. Huang, B., W. Wang, M. Bates, and X. Zhuang. 2008. Three-dimensional superresolution imaging by stochastic optical reconstruction microscopy. Science. 319: 810-813.

51. Wang, Y., J. Schnitzbauer, Z. Hu, X. Li, Y. Cheng, Z.-L. Huang, and B. Huang. 2014. Localization events-based sample drift correction for localization microscopy with redundant cross-correlation algorithm. Opt. Express. 22: 15982-15991.

52. Coltharp, C., R.P. Kessler, and J. Xiao. 2012. Accurate construction of photoactivated localization microscopy (PALM) images for quantitative measurements. PLoS One. 7: e51725.

53. Levet, F., E. Hosy, A. Kechkar, C. Butler, A. Beghin, D. Choquet, and J.-B. Sibarita. 2015. SR-Tesseler: a method to segment and quantify localization-based superresolution microscopy data. Nat. Methods. 12: 1065-1071.

54. Pendergrass, W., N. Wolf, and M. Poot. 2004. Efficacy of MitoTracker Green and CMXrosamine to measure changes in mitochondrial membrane potentials in living cells and tissues. Cytometry A. 61: 162-169.

55. Poot, M., and R.H. Pierce. 1999. Detection of changes in mitochondrial function during apoptosis by simultaneous staining with multiple fluorescent dyes and correlated multiparameter flow cytometry. Cytometry. 35: 311-317.

56. Keij, J.F., C. Bell-Prince, and J.A. Steinkamp. 2000. Staining of mitochondrial membranes with 10-nonyl acridine orange, MitoFluor Green, and MitoTracker Green is affected by mitochondrial membrane potential altering drugs. Cytometry. 39: 203210.

57. Buckman, J.F., H. Hernández, G.J. Kress, T.V. Votyakova, S. Pal, and I.J. Reynolds. 2001. MitoTracker labeling in primary neuronal and astrocytic cultures: influence of 
mitochondrial membrane potential and oxidants. J. Neurosci. Methods. 104: 165176.

58. Bates, M., B. Huang, G.T. Dempsey, and X. Zhuang. 2007. Multicolor superresolution imaging with photo-switchable fluorescent probes. Science. 317: 17491753.

59. van de Linde, S., A. Löschberger, T. Klein, M. Heidbreder, S. Wolter, M. Heilemann, and M. Sauer. 2011. Direct stochastic optical reconstruction microscopy with standard fluorescent probes. Nat. Protoc. 6: 991-1009.

60. Huang, B., M. Bates, and X. Zhuang. 2009. Super-resolution fluorescence microscopy. Annu. Rev. Biochem. 78: 993-1016.

61. Lee, S.-H., J.Y. Shin, A. Lee, and C. Bustamante. 2012. Counting single photoactivatable fluorescent molecules by photoactivated localization microscopy (PALM). Proc. Natl. Acad. Sci. USA. 109: 17436-17441.

62. Nino, D., N. Rafiei, Y. Wang, A. Zilman, and J.N. Milstein. 2017. Molecular Counting with Localization Microscopy: A Bayesian Estimate Based on Fluorophore Statistics. Biophys. J. 112: 1777-1785.

63. Nino, D., D. Djayakarsana, and J.N. Milstein. 2019. Nanoscopic stoichiometry and single-molecule counting. Small Methods. : 1900082.

64. Nath, K., and A.L. Koch. 1970. Protein degradation in Escherichia coli. I. Measurement of rapidly and slowly decaying components. J. Biol. Chem. 245: 2889-2900.

65. Bal, W., A.M. Protas, and K.S. Kasprzak. 2011. Genotoxicity of metal ions: chemical insights. Met. lons Life Sci. 8: 319-373.

66. Haeberlin, A., A. Zurbuchen, S. Walpen, J. Schaerer, T. Niederhauser, C. Huber, H. Tanner, H. Servatius, J. Seiler, H. Haeberlin, J. Fuhrer, and R. Vogel. 2015. The first batteryless, solar-powered cardiac pacemaker. Heart Rhythm. 12: 1317-1323. 